\title{
Erratum to: Tolvaptan for Heart Failure Patients with Volume Overload
}

\author{
Masatsugu Hori
}

Published online: 26 November 2011

(C) Springer Science+Business Media, LLC 2011

\section{Erratum to: Cardiovase Drugs Ther DOI 10.1007/s10557-011-6298-4}

In the reference list the first reference should be the more recent reference 'Japanese Circulation Society. Guidelines for the diagnosis and treatment of cardiovascular disease (Joint Study Group Report 2009): guidelines for treatment of chronic heart failure (revised 2010). http://www.j-circ.or.jp/guideline/pdf/ JCS2010_matsuzaki_h.pdf. Accessed 13 April 2011.

Following this change, the increase in body weight on page 1 should read ' $2-3 \mathrm{~kg}$ ' not ' $2-5 \mathrm{~kg}$ '. Also, the guidelines should be referred to in the text as 'Guidelines for Treatment of Chronic Heart Failure (revised 2010).'

In addition, the full meaning of SIADH is 'Syndrome of inappropriate secretion of antidiuretic hormone' not 'Syndrome of inappropriate antidiuretic hormone secretion'.

On page 3 , the phase 1 study should be cited as reference [10] not reference [13].

Finally, the full citations for references $10,11,12,13$, $14,15,16$ and 17 should be 'e-pub ahead of print' not 'submitted'
The online version of the original article can be found at http:// dx.doi.org/10.1007/s10557-011-6298-4.

M. Hori $(\bowtie)$

Osaka Medical Center for Cancer and Cardiovascular Diseases,

1-3-3 Nakamichi, Higashinari-ku,

Osaka 537-8511, Japan

e-mail: hori-ma@mc.pref.osaka.jp 